\title{
Basic Fibroblast Growth Factor Increases Long-Term Survival of Spinal Motor Neurons and Improves Respiratory Function after Experimental Spinal Cord Injury
}

\author{
Yang Dong Teng, ${ }^{1}$ Italo Mocchetti, ${ }^{1}$ Angelo M. Taveira-DaSilva, ${ }^{2}$ Richard A. Gillis, ${ }^{3}$ and Jean R. Wrathall ${ }^{1}$ \\ Departments of ${ }^{1}$ Cell Biology, ${ }^{2}$ Medicine, and ${ }^{3}$ Pharmacology, School of Medicine, Georgetown University, Washington, \\ DC 20007
}

\begin{abstract}
Acute focal injection of basic fibroblast growth factor (FGF2) protects ventral horn $(\mathrm{VH})$ neurons from death after experimental contusive spinal cord injury $(\mathrm{SCl})$ at T8. Because these neurons innervate respiratory muscles, we hypothesized that respiratory deficits resulting from $\mathrm{SCl}$ would be attenuated by FGF2 treatment. To test this hypothesis we used a head-out plethysmograph system to evaluate respiratory parameters in conscious rats before and at $24 \mathrm{hr}$ and 7, 28, and $35 \mathrm{~d}$ after $\mathrm{SCl}$. Two groups of rats ( $n=8$ per group) received either FGF2 (3 $\mu \mathrm{g}$ ) beginning 5 min after injury or vehicle (VEH) solution alone. We found significantly increased respiratory rate and decreased tidal volume at $24 \mathrm{hr}$ and $7 \mathrm{~d}$ after $\mathrm{SCl}$ in the VEH-treated group. Ventilatory response to breathing 5 or $7 \%$ $\mathrm{CO}_{2}$ was also significantly reduced. Recovery took place over
\end{abstract}

Traumatic spinal cord injury (SCI) results in the loss of spinal cord tissue and permanent neurological deficits. In $\sim 50 \%$ of patients, injury is initially incomplete; some residual function remains (Bracken et al., 1990). Vertebral fracture or dislocation most frequently causes spinal cord bruising or contusion (Kurtzke, 1977; Riggins and Kraus, 1977). Experimental studies show that the pathophysiology of SCI consists of two phases. The first is the initial mechanical trauma. The second phase includes many pathophysiological and biochemical changes (e.g., ischemia, anoxia, free-radical formation, and excitotoxicity) that occur over hours and days after injury. These "secondary injury" processes can exacerbate the mechanical injury, resulting in additional tissue loss and functional deficits. Therapeutic interventions that can attenuate secondary injury may reduce the overall deficits from SCI (Young, 1993).

Current experimental studies are generally focused on incomplete contusive or compression injuries at thoracic or lower cervical spinal cord levels (Wrathall, 1996). The most obvious functional deficits are in hindlimb sensorimotor function as reflected in abnormal reflexes and coordinated motor function and, specifically, abnormalities in the use of the hindlimbs in locomotion

\footnotetext{
Received Feb. 23, 1999; revised May 28, 1999; accepted June 2, 1999.

This work was supported by National Institutes of Health Grants RO1-NS-35647 and PO1-NS-28130. We thank Ms. Marian Bingaman and Ms. Sadia Aden for their valuable assistance in data processing, immunocytochemistry, and behavioral evaluation. We are grateful to Dr. Bruce J. Trock of the Division of Molecular Epidemiology, Georgetown University (Washington, DC), for his help in statistical analyses. We also thank Scios-Nova (Mountain View, CA) for the generous gift of FGF2.

Correspondence should be addressed to Dr. Jean R. Wrathall, Department of Cell Biology, Neurobiology Division, Georgetown University, 3900 Reservoir Road Northwest, Washington, DC 20007.

Copyright (C) 1999 Society for Neuroscience $0270-6474 / 99 / 197037-11 \$ 05.00 / 0$
}

time. Respiration remained normal in the FGF2-treated group. At $35 \mathrm{~d}$ after injury, histological analyses were used to compare long-term neuron survival. FGF2 treatment doubled the survival of $\mathrm{VH}$ neurons adjacent to the injury site. Because the number of surviving $\mathrm{VH}$ neurons rostral to the injury epicenter was significantly correlated to the ventilatory response to $\mathrm{CO}_{2}$, it is likely that the absence of respiratory deficits in FGF2-treated rats was caused by its neuroprotective effect. Our results demonstrate that FGF2 treatment prevents the respiratory deficits produced by thoracic SCI. Because FGF2 also reduced the loss of preganglionic sympathetic motoneurons after injury, this neurotrophic factor may have broad therapeutic potential for $\mathrm{SCl}$.

Key words: rat; FGF2; motor neurons; tidal volume; respiratory rate; minute ventilation; plethysmograph; ChAT
(Gale et al., 1985; Noble and Wrathall, 1989a; Basso et al., 1995). These deficits are highly correlated to the loss of white matter at the injury site (Noble and Wrathall, 1989a; Behrmann et al., 1992). Experimental acute therapeutic interventions that reduce white matter loss are highly effective in reducing the long-term functional deficits resulting from standardized SCI (Wrathall et al., 1994; Teng and Wrathall, 1997). However, SCI also results in the loss of segmental gray matter with neuronal death by necrosis and apoptosis (Crowe et al., 1997; Lui et al., 1997). Depending on the level of SCI, the neurons that are lost may cause different types of deficits. Because ventral horn $(\mathrm{VH})$ motor neurons in the thoracic cord innervate muscles involved in respiration (Saji and Miura, 1990; Holstege, 1991; Monteau and Hilaire, 1991), we hypothesized that our SCI would produce deficits in respiratory function.

Treatment with the neurotrophic factor basic fibroblast growth factor (FGF2) significantly rescues neurons and improves functional recovery after experimental head trauma and stroke (for review, see Moyer et al., 1998). We found that focal injection of FGF2 into the injury epicenter $5 \mathrm{~min}$ after SCI at T8 rescued spinal VH and intermediolateral (IML) motor neurons adjacent to the injury site at $24 \mathrm{hr}$ after injury and preserved their cholinergic phenotype (Teng et al., 1998b). Therefore, we hypothesized that acute treatment with FGF2 could reduce acute respiratory deficits resulting from loss of $\mathrm{VH}$ neurons. Furthermore, if acute neurotrophic support with FGF2 was sufficient to overcome secondary neuronal injury, improved long-term survival of both $\mathrm{VH}$ and IML neurons should occur.

To test these hypotheses we used a head-out plethysmograph system (Dorato et al., 1983) to examine the effects of SCI at T8 on respiration in conscious rats and the effect of FGF2 treatment on 
a



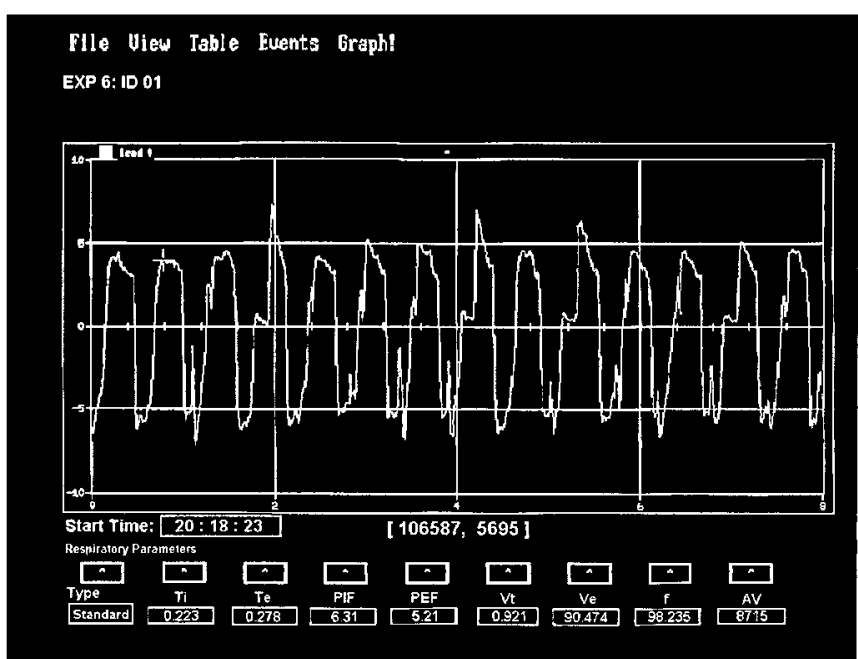

Figure 1. Noninvasive measurements of respiratory function in conscious rats. $a$, Schematic presentation of the restrained head-out plethysmograph system for rodents is shown. $b$, The animals breathe from a funnel fixed in the front wall of a box made of an opaque material. The box surrounds the front two-thirds of the body cylinder of the plethysmograph, and the rear outlet of the box is covered with a piece of bath towel (illustrated by a dashed

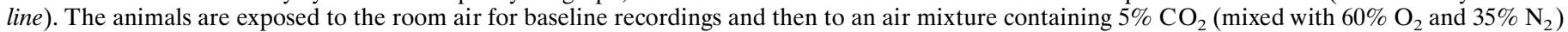
for $5 \mathrm{~min}$, and recording of respiratory activity is continued for another $2 \mathrm{~min}$ (a total recording duration of $7 \mathrm{~min}$ ). After a new baseline is obtained by allowing the animals to breathe room air for at least $20 \mathrm{~min}$, the rats are challenged with a $7 \% \mathrm{CO}_{2}$ gas mixture $\left(\right.$ mixed with $60 \% \mathrm{O}_{2}$ and $\left.33 \% \mathrm{~N}_{2}\right)$. $c$, Computer screen readout of the respiratory flow (i.e., the tracing curve; $y$-axis units, $\mathrm{ml} / \mathrm{sec}$ ) and flow-derived respiratory parameters (e.g., Vt, $f$, and $\mathrm{Ve}$ ) is shown. $A / D$, Analog-to-digital; $A V$, accumulated volume; Exp, experiment; $P E F$, peak expiratory flow; PIF, peak inspiratory flow; Te, expiratory time; $T i$, inspiratory time.

respiratory deficits and the long-term loss of ChAT-positive VH neurons. For evaluating IML neuronal survival, we used ChAT immunocytochemistry and retrograde tracing from their target, the adrenal medulla.

\section{MATERIALS AND METHODS}

\section{Spinal cord injury}

Female Sprague Dawley rats (250-280 gm) were anesthetized with $4 \%$ chloral hydrate $(360 \mathrm{mg} / \mathrm{kg}$, i.p.), and an incomplete spinal cord contusion injury was produced at T8 with a weight drop device $(10 \mathrm{gm} \times 2.5$ $\mathrm{cm})$ as described previously (Wrathall et al., 1985). After SCI, manual expression of bladders was performed twice daily until a reflex bladder was established. Animal care also included housing the rats in pairs to reduce isolation-induced stress, maintaining ambient temperature at $22-25^{\circ} \mathrm{C}$, and using highly absorbent bedding. No prophylactic antibiotics were given.

\section{Administration of FGF2}

On the basis of the results from previous dose-response studies (Teng et al., 1998a), we used either $3 \mu \mathrm{g}$ of FGF2 or vehicle (VEH) solution (both with a $1.5 \mu \mathrm{l}$ final volume). Solutions were infused through a 33 gauge needle, inserted stereotaxically at the midline of the injury site $1 \mathrm{~mm}$ below the dura, at a rate of $0.21 \mu \mathrm{l} / \mathrm{min}$ beginning $5 \mathrm{~min}$ post injury (p.i.). The infusion lasted $\sim 7.2$ min. Recombinant human FGF2 (a gift from Scios-Nova, Mountain View, CA) was diluted to $2 \mu \mathrm{g} / \mu \mathrm{l}$ in sterile saline with $0.1 \mathrm{mg} / \mathrm{ml}$ bovine serum albumin (Boehringer Mannheim, Indianapolis, IN), final $\mathrm{pH}$ 7.4. Control rats received sterile saline with 0.1 $\mathrm{mg} / \mathrm{ml}$ bovine serum albumin, $\mathrm{pH}$ 7.4. After the injection, the needle was kept in the spinal cord for an additional 2 min to reduce the possibility of losing injected solution from the site. The biological activity of FGF2 was stated by the supplier to be $1.277 \mathrm{ng} / \mathrm{ml}$ protein for $\mathrm{ED}_{50}$ in $3 \mathrm{~T} 3$ fibroblasts. We confirmed the biological activity of FGF2 used in this study by an in vitro MAP kinase phosphorylation assay in C6-2B glioma cells (Mocchetti et al., 1996).

\section{Experimental protocol}

The experiments were performed according to a randomized block design. Experimental group size was decided on the basis of power analysis of the outcome measure data of a previous study (Teng et al., 1998b). According to this analysis, with seven rats per group there is an
$87 \%$ probability of detecting an effect $\geq 50 \%$ in $\mathrm{VH}$ neuronal sparing, whereas an $80 \%$ probability exists for detecting an effect $\geq 47 \%$ in IML neuronal sparing at a spinal level $3 \mathrm{~mm}$ caudal to the injury epicenter [see Teng et al. (1998b) for a detailed description of these outcome measures]. The FGF2- and VEH-treated groups ( $n=8$ per group) were behaviorally tested at $1 \mathrm{~d}$ and weekly thereafter through 5 weeks after injury. On day 30 p.i., animals were reanesthetized, and Fluoro-Gold-soaked gel foam was implanted into the adrenal medulla for retrograde labeling of IML neurons (see below). At the end of the experiment (at day 35 p.i.), the animals were reanesthetized, and the spinal cord tissue and adrenal glands were fixed by perfusion for histopathological analyses and confirmation that the Fluoro-Gold-soaked gel foam pieces were implanted properly. All animals survived the entire study except one in the VEHtreated group that died at day 31 p.i., because of aggressive behavior by a cage mate, for a final $n=7$ on day 35 p.i.. All values are expressed as mean \pm SEM. Statistical significance was defined at the $p<0.05$ level. The statistical tests used are described below and also specified in the figure legends. All experimental procedures were performed in strict accordance with the Laboratory Animal Welfare Act, Guide for the Care and Use of Laboratory Animals (National Institutes of Health, DHEW publication number 78-23, revised 1978), after review and approval by the Animal Care and Use Committee of Georgetown University.

\section{Monitoring of respiratory parameters by plethysmograph}

Experiments were conducted in unanesthetized, awake, spontaneously breathing rats at $24 \mathrm{hr}$ before SCI, at $24 \mathrm{hr}$ p.i., and weekly afterward at 1,4 , and 5 weeks p.i.. Preliminary studies repeatedly showed that respiratory function recovered to the preinjury level at 2 weeks p.i. $(n=3$ and 4, VEH- and FGF2-treated animals, respectively; data not shown). Thus, we omitted recordings at weeks 2 and 3 p.i..

Noninvasive measurements of respiratory rate, tidal volume, and minute ventilation. Animals were placed in the body cylinder of the plethysmograph (Fig. 1a) for $60 \mathrm{~min}$ per day for at least $5 \mathrm{~d}$. This acclimation enabled them to adjust to the environment and eliminated physical signs of stress (i.e., defecation, urination, or bloody secretions in the eyes and nose). Noninvasive measurements of respiratory function in conscious rats were performed with a restrained head-out plethysmograph specially designed for rodents (Buxco Electronics, Sharon, CT) (Fig. 1a). The plethysmograph apparatus has a neck seal that prevents leakage of air from between the animal's neck and the plethysmograph opening. Displacement of the thoracic wall produced by the animal's respiratory 
movements causes changes in the cylinder pressure, and this results in air flowing across a pneumotachograph located on the wall of the cylinder. The pressure drop across the pneumotachograph is measured with a pressure transducer and is proportional to the flow. This signal is amplified and integrated into volume. From measurements of volume and flow, a computer and appropriate software provide respiratory parameters, such as respiratory rate $(f)$, tidal volume $(\mathrm{Vt})$, minute ventilation $(\mathrm{Ve})$, peak inspiratory flow, peak expiratory flow, inspiratory time, expiratory time, and accumulated volume (Fig. 1c). An additional opening on the wall of the box allows volume calibration by injecting and removing air from the box with a calibrated syringe.

The noise level in the laboratory was kept to a minimum to avoid startling the animals. Furthermore, the animals were visually isolated from the investigators by means of a chamber made of an opaque material that surrounded and covered the front end of the body plethysmograph (Fig. 1b). Baseline recordings lasted for $4 \mathrm{~min}$. To minimize possible potential data variations further because of diurnal influences, all the plethysmograph evaluations were performed during the afternoon portion of the day.

Measurement of ventilatory response to carbon dioxide. For measurement of the ventilatory response to $\mathrm{CO}_{2}$, animals were exposed to air containing 5 and $7 \% \mathrm{CO}_{2}$. The animals breathed from a funnel fixed in the front wall of a chamber made of an opaque material (Fig. 1b). The animals were exposed to the gas mixture containing $5 \% \mathrm{CO}_{2}$ (mixed with $60 \% \mathrm{O}_{2}$ and $35 \% \mathrm{~N}_{2}$ ) for $5 \mathrm{~min}$ with recording of respiratory activity for another $2 \mathrm{~min}$ (a total recording duration of $7 \mathrm{~min}$ ). The animals were then allowed again to breathe room air for at least $20 \mathrm{~min}$. A new baseline was obtained, and subsequently the procedure was repeated for the $7 \% \mathrm{CO}_{2}$ gas mixture (mixed with $60 \% \mathrm{O}_{2}$ and $33 \% \mathrm{~N}_{2}$ ).

\section{Behavioral evaluations of functional deficits}

Tests of functional deficits were performed by one individual blind to the treatments, and the results were confirmed in separate evaluations by a second independent investigator who was blind to experimental treatments for the rats. At each time point a battery of tests of hindlimb reflexes as well as coordinated use of hindlimbs was used, as described previously (Gale et al., 1985; Kerasidis et al., 1987). The reflexes tested included toe spread, placing, withdrawal in response to extension, pressure or brief pain, righting, and the reflex to lick the toes in response to heat. Coordinated motor activity assessed included open-field locomotion, swimming, and ability to maintain position on an incline plane. Results in individual tests were summarized, and overall hindlimb impairment was estimated with a combined behavioral score (CBS) that ranges from 0 (normal rat) to 100 (rat with no evidence of hindlimb function). The CBS was developed on the basis of initial injury doseresponse studies (Gale et al., 1985). It exhibits a normal distribution, as formally tested with the Wilk-Shapiro procedure (Shapiro and Wilk, 1965), and was designed as a parametric statistic to provide a continuous measure of overall hindlimb deficits that is correlated to injury severity. It has greater statistical power than any of its component behavioral tests (Gale et al., 1985) and is significantly correlated with both the degree of initial mechanical injury (Panjabi and Wrathall, 1988) and chronic histopathology (Noble and Wrathall, 1985, 1989a).

In addition, a more detailed examination of open-field locomotion was performed using an expanded scale that ranges from 0 to 21 , where 0 reflects no locomotory function and 21 reflects a normal performance (Basso et al., 1995). This "BBB Scale" has been adopted by the multicenter animal spinal cord injury study (MASCIS) group engaged in preclinical screening of potential therapeutic agents for SCI (Basso et al., 1996). Therefore, use of the BBB as an outcome measure after experimental SCI supports an easier interlaboratory comparison of results.

\section{Fluoro-Gold retrograde labeling of IML neurons in the spinal} cord that innervate the adrenal medulla

At day 30 p.i., animals were anesthetized, and a dorsal laparotomy was performed on each rat. The adrenal glands were exposed (Schramm et al., 1975; Blottner and Baumgarten, 1992). A piece of gel foam (Upjohn, Kalamazoo, MI) of $1 \mathrm{~mm}^{3}$, soaked previously with a $2 \%$ aqueous solution of Fluoro-Gold (Fluorochrome, Englewood, $\mathrm{CO}$ ) and air dried for 2 min, was implanted into each adrenal medulla. The stitch channel produced by the gel foam insertion was sealed with tissue glue (Histoacryl; Braun, Melsungen, Germany), and the dermal wound was sutured. The animals were allowed to recover for $4 \mathrm{~d}$ and then, at day 35 p.i., perfused for histopathology and fluorescent microscopy, as described below.

\section{Histopathology}

After the 5 week behavioral and respiratory evaluations, animals were anesthetized with $4 \%$ chloral hydrate and perfused intracardially with saline followed by $4 \%$ paraformaldehyde in phosphate buffer, $\mathrm{pH}$ 7.4. Spinal cord tissue was removed from the vertebral canal, and a $1.5 \mathrm{~cm}$ segment centered at the injury site was excised, placed in fixative for an additional hour, equilibrated with increasing concentrations of sucrose solutions $(10-20 \%)$, and frozen with dry ice-isopentane $\left(-50^{\circ} \mathrm{C}\right)$. Eight spinal cords in the FGF2-treated group and seven in the VEH-treated group were sectioned for morphometric, immunocytochemical, and fluorescent microscopy analyses. Serial $20 \mu \mathrm{m}$ cross sections were cut with a Jung Frigicut 2800 E cryostat and mounted with five sections (100 $\mu \mathrm{m}$ of tissue) per slide on slides that were coated with 3-aminopropyltriethoxysilane (Koo et al., 1988). Spinal cords were processed as described previously (Wrathall et al., 1994) with cords from the VEH- and FGF2-treated groups blocked together and serial sections from spinal cords of the two groups pair-mounted onto the same slides to allow comparison of identically processed tissue. All morphological analyses were done with tissue identified only by animal number; the evaluator was blind to the treatment group until after the primary data were collected.

Every 10th slide was stained with luxol-blue/hematoxylin and eosin and was examined for lesion cells and cavities as described previously (Noble and Wrathall, 1985). The results were used to identify the injury epicenter (region of maximal damage) and to compare chronic lesion length between the two experimental groups. For assessment of neuroprotection, slides representing the epicenter and specific locations rostral and caudal to it were analyzed for the presence of surviving $\mathrm{VH}$ and IML neurons that exhibited Nissl substance, a euchromatic nucleus, and a distinct nucleolus (Teng et al., 1998b). Because Saji and Miura (1990) reported that at a lower thoracic level (i.e., T7) respiratory motoneurons are distributed throughout the $\mathrm{VH}$ area, all the neurons in the $\mathrm{VH}$ that met the criteria of appropriate size and location (Teng et al., 1998b) were counted.

Additional slides containing sections from $4 \mathrm{~mm}$ rostral and caudal to the epicenter and also $7 \mathrm{~mm}$ rostral to the epicenter were air-dried, coverslipped with glycerin-mounting media, and examined by fluorescence microscopy (wide-band ultraviolet excitation, 340-389 $\mathrm{nm}$ ) to visualize Fluoro-Gold-labeled IML neurons. The average number of labeled neurons was determined on the basis of counts from both the left and right IML in the five tissue sections representing a particular rat present on each slide.

For measurement of white matter (WM) sparing, sections of lesion epicenter stained with luxol-blue/hematoxylin and eosin were projected. Areas of WM, hypomyelinated WM, lesion cells, and cavities were traced as described previously (Noble and Wrathall, 1985). The tracings were digitized, and areas of total WM were calculated with a SigmaScan image analysis system (Jandel Scientific, San Rafael, CA).

\section{Immunocytochemistry of ChAT}

Additional sets of slides from 3 and $4 \mathrm{~mm}$ rostral and caudal to the epicenter were used for quantitative ChAT immunocytochemistry (Sofroniew et al., 1993; Teng et al., 1998b). Briefly, an anti-ChAT polyclonal antibody (Chemicon, Temecula, CA) was used in a modified peroxidaseantiperoxidase procedure, with 3,3'-diaminobenzidine tetrahydrochloride (DAB) as a chromogen. The analysis was performed on slides from all FGF2- and VEH-treated animals (FGF2, $n=8$; VEH, $n=7$ ). For comparing the results with those in normal rats, corresponding spinal sections of three laminectomy-control animals were also processed for ChAT immunocytochemistry at the same time. ChAT-positive images of VH and IML neurons were captured using a constant threshold for DAB density using a personal computer Image-pro plus system (Media Cybernetics, Silver Spring, MD).

\section{Statistical analyses}

CBS data were analyzed statistically using repeated measures ANOVA, followed by Tukey's test for multiple comparisons between groups as used in previous studies (e.g., Wrathall et al., 1994). BBB scores were also analyzed by ANOVA with repeated measures (Basso et al., 1995), followed by Tukey's test for differences at individual time points. The same statistical tests were used for analyzing respiratory data, as well as for comparing numbers of ChAT-positive neurons at 3 and $4 \mathrm{~mm}$ rostral and caudal to the injury site. For comparison of areas of spared WM at the lesion epicenter in FGF2- and VEH-treated groups and for the com- 


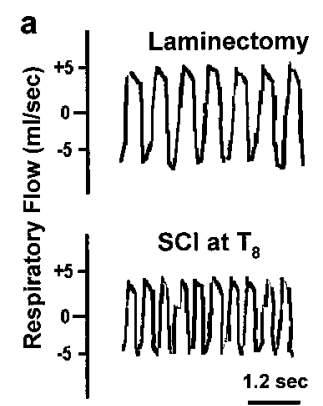

Under room air ventilation

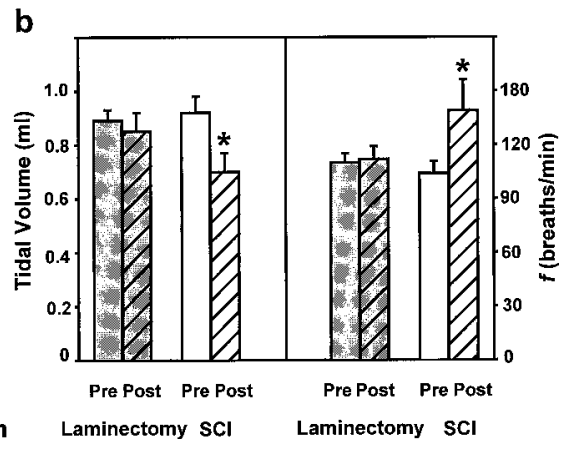

Figure 2. Effects of incomplete contusive SCI at T8 on respiratory function at $24 \mathrm{hr}$ after injury. $a$, Plethysmograph tracings of respiratory flow rate (units, $\mathrm{ml} / \mathrm{sec}$ ) obtained from conscious rats breathing room air $24 \mathrm{hr}$ after laminectomy alone (top) or laminectomy and SCI (bottom). b, Comparison of average tidal volume (left) and $f($ right $)$ before (Pre) and 24 $\mathrm{hr}$ after (Post) surgery for groups of rats subjected to laminectomy alone or SCI (10 gm $\times 2.5 \mathrm{~cm}$ weight drop) at T8 $(n=3$ per group $)$. Asterisks indicate a significant difference relative to presurgery values (unpaired $t$ test, $p<0.05$ ).

parison of lesion length in the two groups, unpaired Student's $t$ tests were used.

\section{RESULTS}

\section{Acute respiratory effects of $\mathrm{SCl}$ at the T8 vertebral level}

Compared with preinjury rats, rats at $24 \mathrm{hr}$ after SCI demonstrated a significant decrease in Vt along with a significant increase in $f$ (Fig. 2b). Thus, their pattern of breathing was changed; it was more shallow and rapid than before injury (Fig. $2 a$ ). Control rats that underwent laminectomy alone showed no significant alterations in either Vt or $f$ at $24 \mathrm{hr}$ after surgery (Fig. 2b). These studies established that SCI at T8 produced a significant effect on respiration as evaluated in conscious rats.

\section{Effects of SCl and FGF2 treatment on respiratory function}

We examined respiration in rats before injury to establish normal parameters. Rats were then subjected to SCI and randomized to receive either FGF2 ( $3 \mu \mathrm{g}$, focally injected into the injury site) or VEH solution beginning $5 \mathrm{~min}$ after SCI. Respiration was reevaluated in the conscious rats at $24 \mathrm{hr}$ and 7, 28, and $35 \mathrm{~d}$ after surgery. In addition to recording baseline respiration with room air ventilation, we challenged rats with air mixtures containing 5 or $7 \% \mathrm{CO}_{2}$, as described in Materials and Methods. This was done to determine the effect of SCI on the central chemoreceptor-mediated response to $\mathrm{CO}_{2}$.

At $24 \mathrm{hr}$ after SCI, the VEH-treated control group exhibited a decrease in Vt $(0.69 \pm 0.0$ vs $0.87 \pm 0.1 \mathrm{ml} ; p<0.05$, repeated measures ANOVA with Tukey's procedure) and an increase in $f$ $(128 \pm 3.6$ vs $103 \pm 2.9$ breaths $/$ min; $p<0.05$, repeated measures ANOVA with Tukey's procedure; Fig. 3). The decrease in Vt and increase in $f$ were maintained to $7 \mathrm{~d}$ p.i.. Normal $\mathrm{Vt}$ and $f$ were restored at 28 and $35 \mathrm{~d}$ after injury (Fig. 3). The Ve with room air was not significantly altered from preinjury values at any time measured after SCI (Fig. 3).

The VEH-treated rats showed a dramatic decrease in the ventilatory response to $\mathrm{CO}_{2}$. The Ve when breathing air containing 5 or $7 \% \mathrm{CO}_{2}$ was significantly decreased at $24 \mathrm{hr}$ p.i. compared with that observed before the injury (Fig. 4). Furthermore, the slope of the regression line showing the ventilatory response

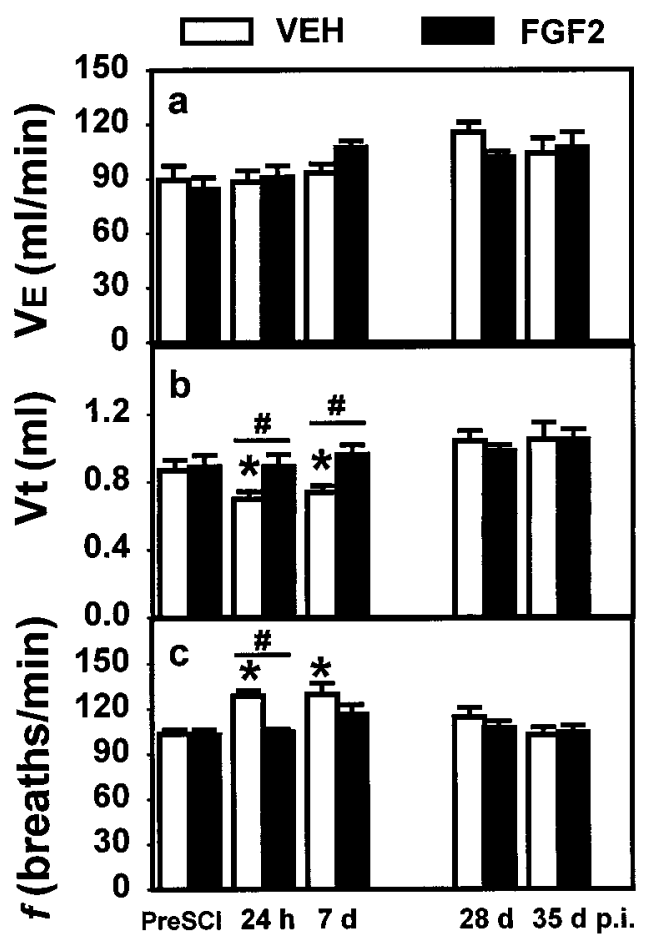

Figure 3. Effects of SCI and FGF2 treatment on respiratory parameters repeatedly measured over 5 weeks after SCI. Vertical bars represent the average $\mathrm{Ve}(a), \mathrm{Vt}(b)$, and $f(c)$ for groups that were subjected to SCI (10 $\mathrm{gm} \times 2.5 \mathrm{~cm}$ weight drop) and then received either VEH alone (open bars; $n=8$ until day 30 p.i.; $n=7$ at day 35 p.i.) or $3 \mu \mathrm{g}$ of FGF2 (solid bars; $n=8)$. $a$, There was no significant effect of SCI or treatment with FGF2 on Ve. $b$, Vt was significantly reduced in the VEH-treated group at $24 \mathrm{hr}$ and $7 \mathrm{~d}$ p.i. compared with that in the preinjury group or the FGF2-treated group evaluated at the same time after injury. $c, f$ was significantly higher in the VEH-treated group at $24 \mathrm{hr}$ and $7 \mathrm{~d}$ p.i. compared with that in the preinjury group or the FGF2-treated group evaluated at the same time after injury. Symbols indicate a significant $\left({ }^{*} p<0.05\right)$ difference from preinjury values and a significant difference between VEH- and FGF2-treated groups at the same time ("two-way repeated measures ANOVA followed by Tukey's procedure).

to different $\mathrm{CO}_{2}$ concentrations was significantly reduced for the VEH-treated group at $24 \mathrm{hr}$ after SCI compared with that for the same rats before injury (Fig. 5). The abnormalities of response to $7 \% \mathrm{CO}_{2}$ were still significant at $7 \mathrm{~d}$ p.i., although they could respond adequately to $5 \% \mathrm{CO}_{2}$ (Fig. 4). At 28 and $35 \mathrm{~d}$ the response to both 5 and $7 \% \mathrm{CO}_{2}$ had recovered to preinjury levels (data not shown).

The FGF2-treated group did not show any significant deficits in baseline Ve, Vt, or $f$ at any of the time points examined (Fig. 3). Treatment with FGF2 prevented both the decrease in $\mathrm{Vt}$ and the increase in $f$ seen in the $\mathrm{VEH}$-treated group at $24 \mathrm{hr}$ and $7 \mathrm{~d}$ after injury. In addition, the ventilatory response to $\mathrm{CO}_{2}$ that was severely impaired in the VEH-treated animals at $24 \mathrm{hr}$ and $7 \mathrm{~d}$ after SCI remained normal in the FGF2-treated group (Figs. 4, 5).

\section{Body weight changes after SCI}

SCI caused a small and statistically insignificant decrease in body weight at $24 \mathrm{hr}$ p.i. relative to that before injury (data not shown). There was no significant difference in body weight between the VEH- and FGF2-treated groups at any time point (repeated measure ANOVA, $p>0.05)$. We observed an increase in the 


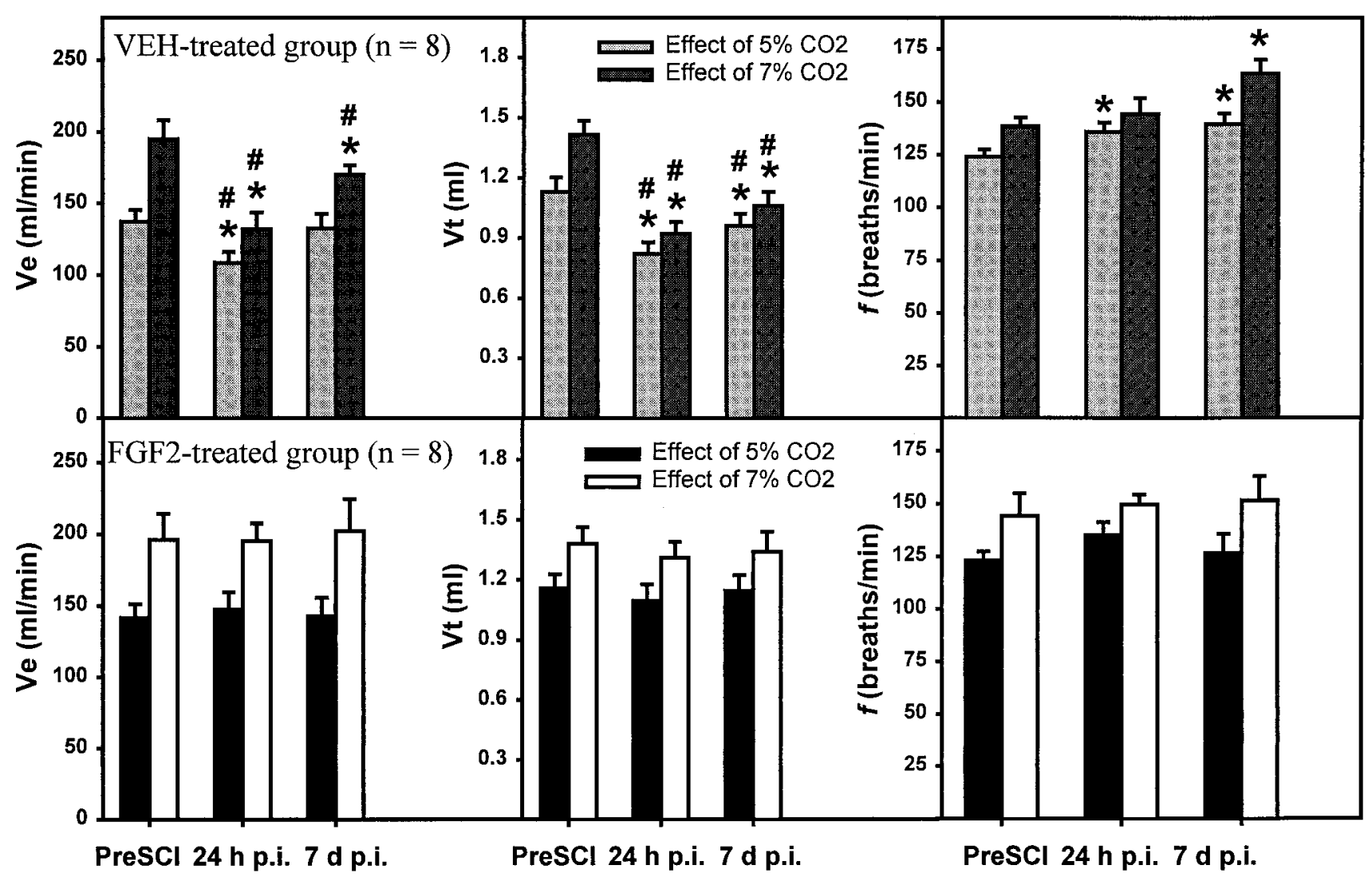

Figure 4. Effects of SCI and FGF2 treatment on the respiratory response to breathing air mixtures containing 5 or $7 \% \mathrm{CO}_{2}$ at $24 \mathrm{hr}$ and $7 \mathrm{~d}$ after SCI. Vertical bars represent the average $\mathrm{Ve}, \mathrm{Vt}$, and $f$ while breathing 5 or $7 \% \mathrm{CO}_{2}$ for the $\mathrm{VEH}$ - and FGF2-treated groups of rats whose baseline respiratory parameters are shown in Figure 3. Symbols indicate significant $\left({ }^{*} p<0.05\right)$ differences from values at $24 \mathrm{hr}$ before SCI and a significant difference between VEH- and FGF2-treated groups at the same time after SCI (\#two-way repeated measures ANOVA followed by Tukey's procedure).

values of $\mathrm{Vt}$ and $\mathrm{Ve}$ in both experimental groups (Fig. 3) along with an increase of their body weight at 28 and 35 d p.i. (data not shown). However, dividing Vt by body weight showed that there was no significant difference between body weight-adjusted Vt values (i.e., in units of $\mathrm{ml} / \mathrm{kg}$ ) before SCI and at $28 \mathrm{~d}$ after injury for either group (data not shown).

\section{Effect of FGF2 on hindlimb and bladder function after $\mathbf{S C I}$}

Rats demonstrated profound impairment of hindlimb function at $1 \mathrm{~d}$ after SCI, including areflexia and lack of coordinated motor functions such as locomotion. Thereafter, partial recovery of function was seen until a plateau was reached at 3-4 weeks reflecting the long-term deficits characteristic of this degree of SCI (Gale et al., 1985; Noble and Wrathall, 1989a). The focal microinjection of FGF2 did not reduce overall hindlimb functional deficits, as assessed by the CBS (Fig. $6 a$ ) or by the BBB scoring system (Fig. $6 b$ ) that provides a more detailed evaluation of locomotion (Basso et al., 1995). In addition, FGF2 treatment did not affect the speed of recovery of hindlimb function as evaluated by CBS and BBB (Fig. 6).

After SCI, micturation is lost, and manual expression of the bladder is required until a "reflex bladder" is established, usually in the second week after this degree of SCI. Treatment with FGF2 did not change the number of days required to develop a reflex bladder $(6.88 \pm 0.30$ vs $6.63 \pm 0.38$ day $)$.

\section{Histopathological examination of the effect of FGF2 on SCI}

In this model of SCI (Noble and Wrathall, 1985, 1989a,b), the lesioned area of the cord exhibits an elongated ovoid form with maximal tissue loss at the so-called "lesion epicenter." The lesion tapers rostral and caudal to the epicenter, with its most distal elements ending in the dorsal funicular white matter.

To determine whether FGF2 spared white matter, the crosssectional profile of epicenters was examined for the residual area of total white matter. The overall outlines of the lesion epicenters from the VEH- and FGF2-treated groups looked comparable (Fig. 7). The epicenters were characterized by a peripheral and incomplete rim of residual, hypomyelinated white matter (Noble and Wrathall, 1985, 1989a; Wrathall et al., 1998). There was a very occasional presence of the most peripheral elements of gray matter that did not show any apparent difference between the two groups. This residual rim surrounded the central lesion that consisted of cavities and a loose network of non-neuronal cells.

The images of the spinal cord sections were further analyzed using morphometric techniques. Determinations of white matter area in sections of the epicenter demonstrated that there was no significant difference between the two groups in the average area of residual total white matter at the lesion epicenter $[0.65 \pm 0.07$ $\mathrm{mm}^{2}$ (FGF2) vs $0.60 \pm 0.06 \mathrm{~mm}^{2}$ (VEH)].

The measurement of longitudinal lesion lengths also did not indicate any significant effect of FGF2. The average lesion length 


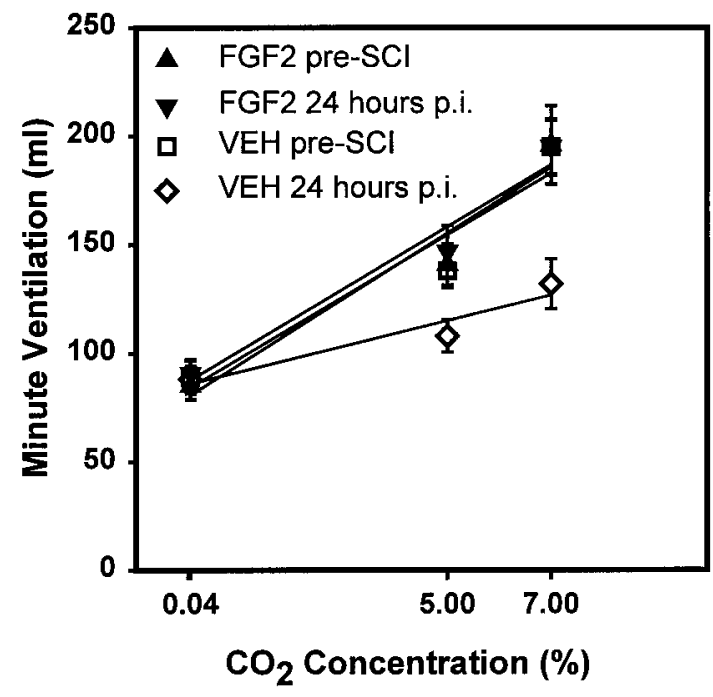

Figure 5. Effect of $\mathrm{CO}_{2}$ concentration on minute ventilation before and at $24 \mathrm{hr}$ after SCI. Symbols represent the average ( \pm SEM; $n=8)$ minute ventilation for the VEH-treated group at $24 \mathrm{hr}$ before $(\square)$ and $24 \mathrm{hr}$ after SCI $(\diamond)$ and the FGF2-treated group at $24 \mathrm{hr}$ before $(\boldsymbol{\Delta})$ and $24 \mathrm{hr}$ after $\mathrm{SCI}(\boldsymbol{\nabla})$ when breathing air containing $0.04 \%$ (room air), $5 \%$, or $7 \% \mathrm{CO}_{2}$. Linear regression lines are presented for each group and time point. There was a significant correlation between $\mathrm{Ve}$ and $\mathrm{CO}_{2}$ concentrations before SCI for the groups of rats that were later injured and treated with VEH $\left(r^{2}=0.9455\right)$ or FGF2 $\left(r^{2}=0.9213\right)$. A strong and significant correlation was also seen at $24 \mathrm{hr}$ after SCI for both the VEH-treated group $\left(r^{2}=\right.$ $0.9619)$ and the FGF2-treated group $\left(r^{2}=0.91645\right)$. However, the average slope of the regression lines was significantly different at $24 \mathrm{hr}$ in the VEH-treated group compared with that in the preinjury group and the FGF2-treated group either before or at $24 \mathrm{hr}$ after SCI $(p<0.001$, Kruskal-Wallis ANOVA on ranks, followed by the Student-NewmanKeuls method, $p<0.05)$.

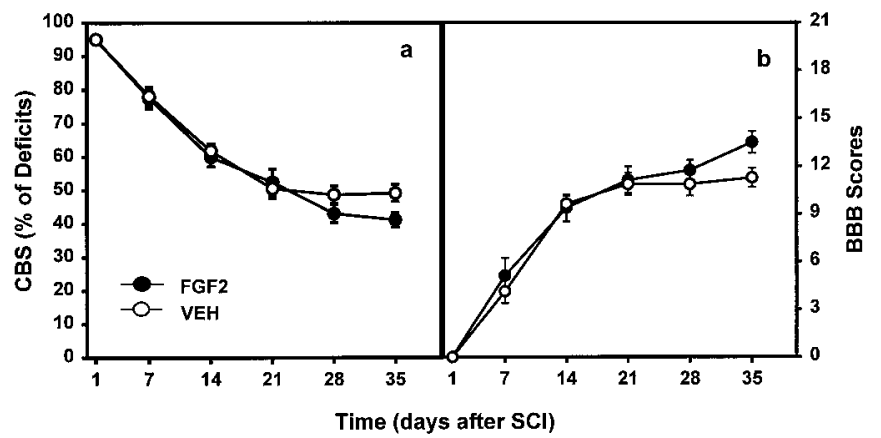

Figure 6. Absence of effect of FGF2 treatment on hindlimb function over time after SCI. Symbols represent the average ( \pm SEM) behavioral scores for groups that received $\mathrm{VEH}$ alone $(\bigcirc ; n=8$ until day 30 p.i.; $n=$ 7 at day 35 p.i.) or $3 \mu \mathrm{g}$ of FGF2 $(\mathbf{0} ; n=8)$. Where no error bar is shown, the SEM was smaller than the symbol. $a$, Overall hindlimb deficits expressed as a CBS (Gale et al., 1985) that ranges from 100 in completely paralyzed rats to 0 in normal rats. $b$, Hindlimb locomotor function graded on an expanded scale [BBB (Basso et al., 1995)] that ranges from 0 in rats with complete hindlimb paralysis to 21 in normal rats. Analysis with repeated measures ANOVA showed no significant effect of FGF2 treatment on either the CBS or BBB.

for the FGF2-treated group was $9.01 \pm 0.47 \mathrm{~mm}$ compared with $9.12 \pm 0.59 \mathrm{~mm}$ for the VEH-control group.

To gain specific information about the neuroprotective effect of FGF2, we measured the longitudinal length of each spinal cord that was devoid of healthy-appearing VH and IML neurons with euchromatic nuclei and prominent nucleoli (Teng et al., 1998b). a



b

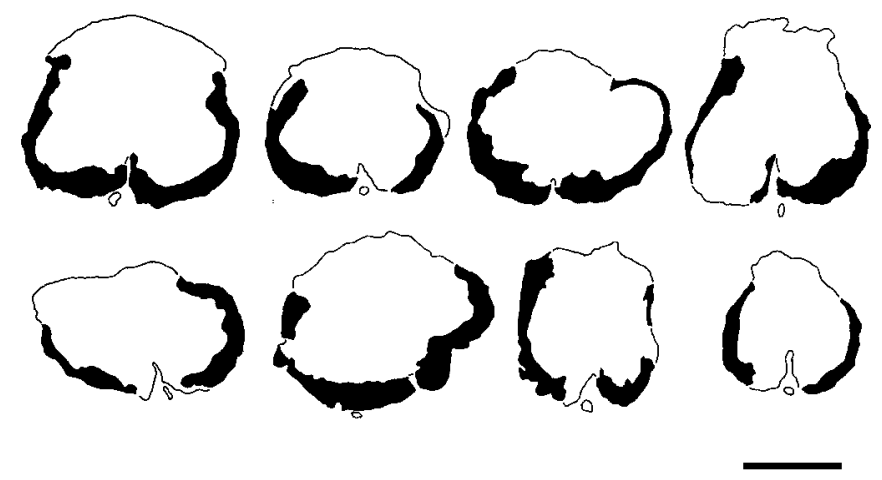

Figure 7. Residual spinal cord white matter at the lesion epicenters 5 weeks after injury. Tracings of sections through the lesion epicenters in rats of the VEH-treated group $(a ; n=7)$ and FGF2-treated group $(b ; n=$ 8 ) show a similar incomplete thin rim of peripheral hypomyelinated white matter. The centers of the lesions (open area in the center of each section) contain cavities and a loose network of lesion cells (data not shown). Scale bar, $1 \mathrm{~mm}$.

This was accomplished by examining a series of sections that were stained with hematoxylin and eosin and were from specified locations at and both rostral and caudal to the lesion epicenters (Teng et al., 1998b). A significant reduction in the length of spinal cord that was devoid of somatic VH motor neurons was found in the FGF2-treated group (Fig. 8c). FGF2 reduced this length by $21 \%$. A $30 \%$ reduction in the length of spinal cord devoid of IML neurons was also observed in the FGF2-treated group (Fig. 8c).

To determine whether neurons spared with FGF2 treatment still maintained their functional phenotype at $35 \mathrm{~d}$ p.i., we compared the numbers of ChAT-positive neurons in the VEH- and FGF2-treated groups. No ChAT-positive neurons were present at the injury epicenter or in tissue $1 \mathrm{~mm}$ adjacent to it. At $2 \mathrm{~mm}$ rostral and caudal to the epicenter, only a few neurons were present. Therefore, spinal sections at 3 and $4 \mathrm{~mm}$ rostral and caudal to the injury epicenter were examined for the number of ChAT-positive neurons (Fig. 8d,e). FGF2 treatment demonstrated an overall significant effect on protecting $\mathrm{VH}$ neurons that were ChAT positive (Fig. $8 d$ ). For example, at $3 \mathrm{~mm}$ rostral and caudal to the injury site, the numbers of $\mathrm{VH}$ neurons in the FGF2-treated group were threefold higher than those in the VEH-treated group. When similar analyses were made for the ChAT-positive IML neurons, we found that FGF2 treatment tripled the number of surviving IML neurons at $3 \mathrm{~mm}$ caudal to the injury site (Fig. 8e).

Retrograde labeling with Fluoro-Gold was used to determine whether surviving IML neurons at $35 \mathrm{~d}$ p.i. maintained connections with their target organ, the adrenal medulla. Post-perfusion examination of adrenal glands showed that all glands were properly implanted with Fluoro-Gold-soaked gel foam. In addition, 

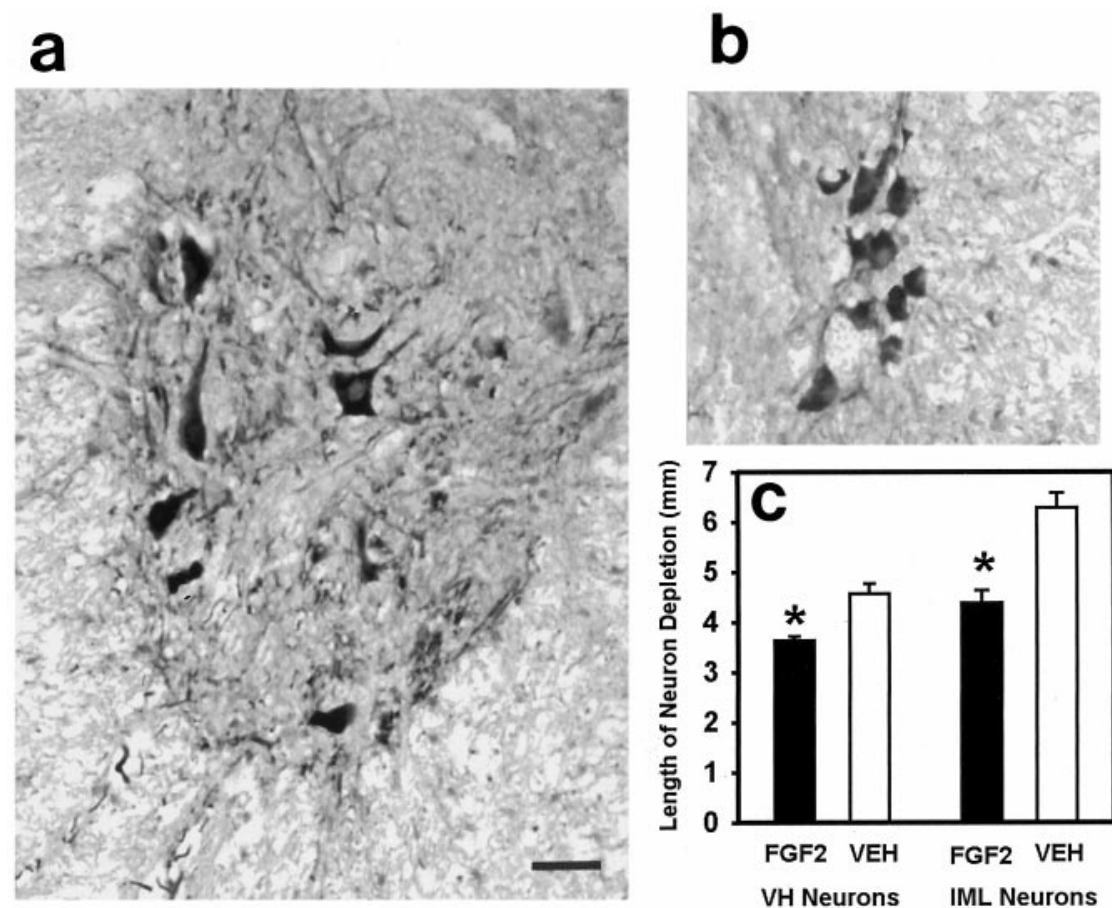

d
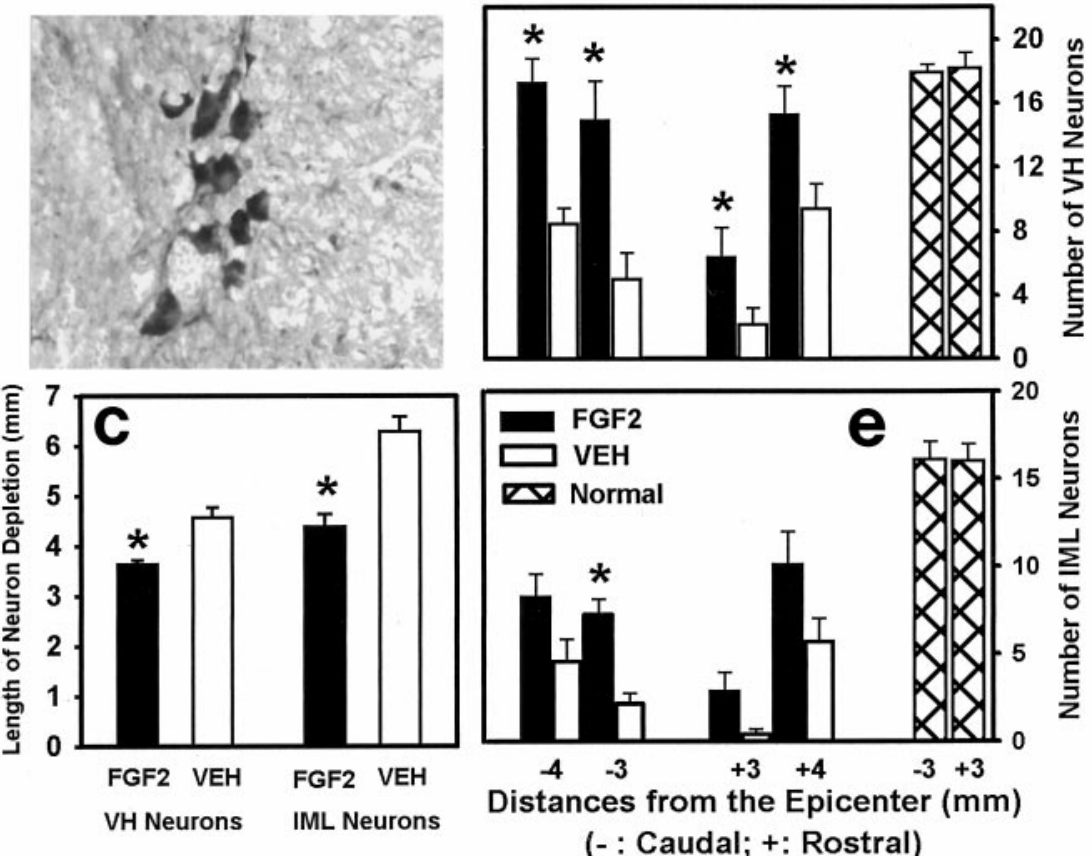

Figure 8. Neuroprotective effects of FGF2 treatment for VH and IML neurons evaluated at 5 weeks after SCI. $a$, $b$, Images of ChAT-positive VH neurons $(a)$ and IML neurons $(b) 4$ mm caudal to the injury epicenter from a FGF2-treated rat. $c$, Effect of FGF2 treatment on the longitudinal depletion of spinal VH and IML neurons, as evaluated in luxol blue/hematoxylin-stained sections. Asterisks indicate significant differences between the FGF2-treated $(n=8)$ and VEH-treated $(n=7)$ groups (unpaired $t$ tests, $p<0.05)$. $d$, Effects of FGF2 treatment on sparing ChAT-positive VH motor neurons. Vertical bars indicate the mean $( \pm \mathrm{SEM})$ number of neurons per tissue section for the VEH-treated (open bars; $n=7)$ and FGF2-treated (solid bars; $n=8$ ) rats at 3 and $4 \mathrm{~mm}$ rostral and caudal to the injury epicenters, as well as from equivalent sections of tissue from normal, uninjured rats (cross-hatched bars; $n=3$ ). Two-way repeated measures ANOVA showed an overall significant effect of FGF2 treatment $(p<0.001)$. Asterisks indicate a significant difference in individual comparisons of the VEH- and FGF2-treated groups at each location (unpaired $t$ tests, $p<0.05$ ). $e$, Effect of FGF2 on the numbers of ChAT-positive IML neurons at 3 and $4 \mathrm{~mm}$ rostral and caudal to the injury epicenters. The FGF2-treated group showed an overall significantly larger number of ChAT-immunoreactive IML neurons (two-way repeated measures ANOVA, $p<0.001$ ) and significant differences in individual comparisons of VEH- and FGF2-treated groups at the specified location (asterisk; unpaired $t$ test, $p<0.05$ )

fluorescent microscopy confirmed that all animals $(n=8$ for FGF2-treated group; $n=7$ for VEH-treated group) had positively labeled IML neurons. In the FGF2-treated group, at spinal cord sections $4 \mathrm{~mm}$ rostral and caudal to the epicenter, clusters of neurons brightly labeled with Fluoro-Gold were seen located in the IML cell columns at lamina VII of Rexed (Fig. 9a). In comparison, significantly fewer IML neurons were labeled in the VEH-treated group (Fig. 9b). Compared with that in the VEHtreated group, the number of Fluoro-Gold-positive IML neurons in the FGF2-treated group was 3.5-fold higher at the spinal level $4 \mathrm{~mm}$ caudal to the injury epicenter and 2.2-fold higher at the level $4 \mathrm{~mm}$ rostral to the epicenter (Fig. 9c). However, the number of IML neurons labeled with Fluoro-Gold in sections $4 \mathrm{~mm}$ caudal to the epicenter was very small $(\leq 6)$ in both groups (Fig. $9 c$ ). When the counting of neurons was done in sections $7 \mathrm{~mm}$ rostral and caudal to the injury site, no difference was observed between the two groups (Fig. 9c).

\section{Correlation between the number of ChAT-positive VH neurons and respiratory function}

The relationship between ChAT-positive VH neurons, spared at 3 and $4 \mathrm{~mm}$ rostral and caudal to the lesion epicenter, and respiratory function, represented by changes in $\mathrm{Vt}$ in response to $\mathrm{CO}_{2}$ at $7 \mathrm{~d}$ after SCI, was examined. Linear regression analysis showed a significant positive correlation between either the number of surviving ChAT-positive VH neurons at $4 \mathrm{~mm}$ rostral $(r=$
$0.654 ; p=0.008)$ or the total at 3 and $4 \mathrm{~mm} \operatorname{rostral}(r=0.522 ; p=$ 0.003 ) to the lesion epicenter and the injury-induced change of $\mathrm{Vt}$ in response to $5 \% \mathrm{CO}_{2}\left(\mathrm{Vt}_{7 \text { d p.i. }}-\mathrm{Vt}_{\text {preinjury }}\right)$ at $7 \mathrm{~d}$ after injury (Fig. 10). Although $\mathrm{VH}$ neurons were spared in even higher numbers at spinal levels caudal to the injury epicenter (Fig. $8 d$ ), there were no significant correlations between changes in $\mathrm{Vt}$ in response to $5 \% \mathrm{CO}_{2}$ and $\mathrm{VH}$ neuron numbers at 3 and $/$ or $4 \mathrm{~mm}$ caudal to the epicenter $(r=0.125$ and $p=0.763 ; r=0.106$ and $p=0.576$, respectively). Moreover, no significant linear correlations were found between changes in $\mathrm{Vt}$ caused by $\mathrm{CO}_{2}$ stimuli and the number of surviving IML neurons at 3 and/or $4 \mathrm{~mm}$ rostral or caudal to the injury site (data not shown).

\section{DISCUSSION}

Our results demonstrate that incomplete contusion injury at T8 results in consistent and significant abnormalities of respiration that can be discerned in conscious rats at $24 \mathrm{hr}$ and 1 week after injury. These include an abnormal pattern of respiration under baseline room air ventilation and a dramatic reduction in the ability of the rats to respond appropriately to breathing higher than normal levels of $\mathrm{CO}_{2}$. A single focal injection of the neurotrophic factor FGF2 administered shortly after contusion is sufficient to prevent SCI-induced respiratory abnormalities. Our data show that the beneficial effect of FGF2 is likely attributable 
a



b

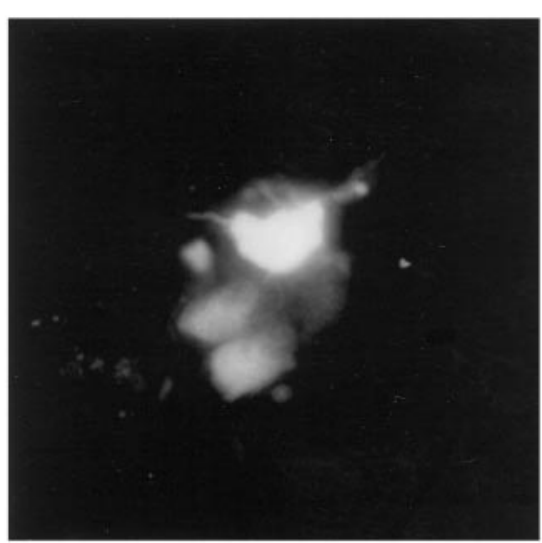

C

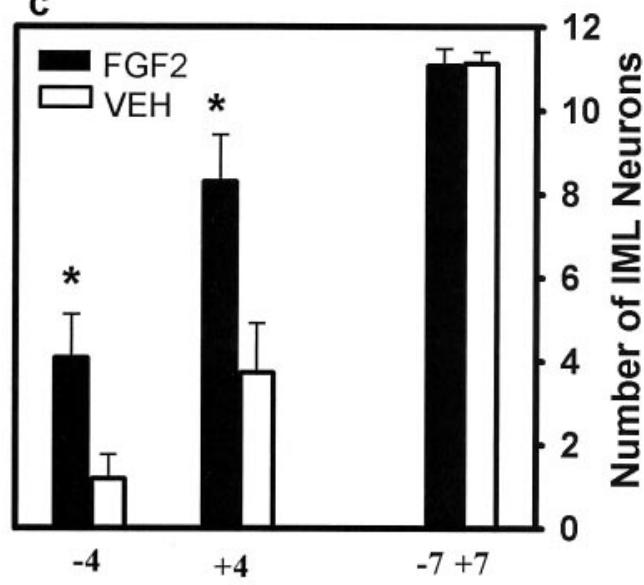

Distances from the Epicenter $(\mathrm{mm})$ (- : Caudal; +: Rostral)

Figure 9. Effect of FGF2 treatment on IML neurons retrogradely labeled by Fluoro-Gold placed in the adrenal medulla. $a$, Cluster of Fluoro-Goldlabeled IML neurons at $4 \mathrm{~mm}$ rostral to the epicenter in an FGF2-treated rat at 5 weeks after SCI. $b$, Reduced numbers of labeled IML neurons at 4 $\mathrm{mm}$ rostral to the epicenter in a VEH-treated animal. Scale bar, $20 \mu \mathrm{m}$. $c$, Quantitative analysis demonstrating that compared with the VEH-treated group (open vertical bars; $n=7$ ), the FGF2-treated group (solid vertical bars; $n=8$ ) had significantly higher numbers of Fluoro-Gold-labeled IML neurons at $4 \mathrm{~mm}$ rostral and caudal to the injury epicenters. At $7 \mathrm{~mm}$ rostral to the epicenter, no difference was observed between the two groups. Asterisks indicate that means are significantly different from those of the VEH-treated group $(p<0.05$, two-way repeated measures ANOVA followed by Tukey's procedure).

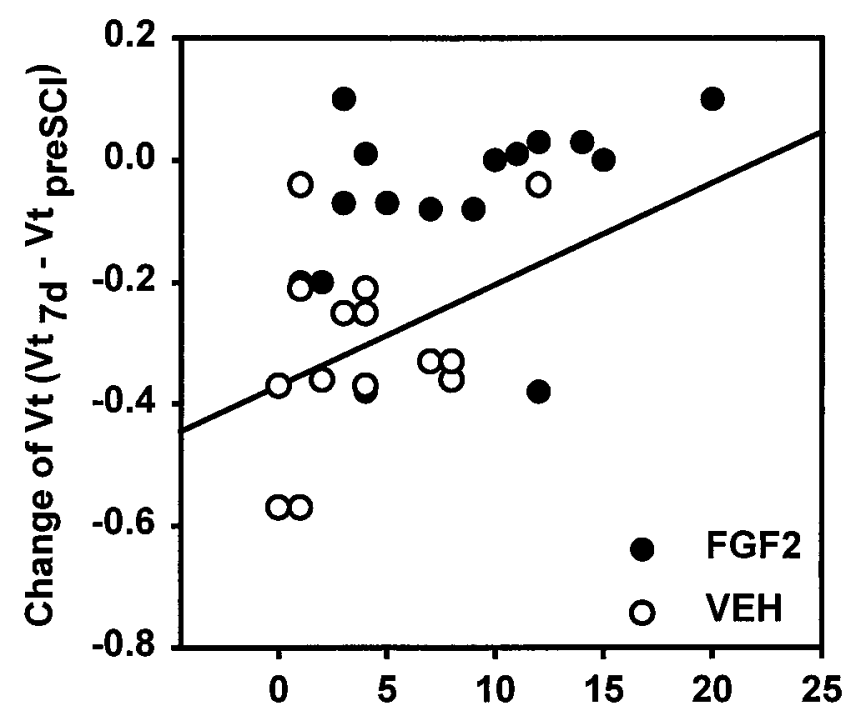

Total Number of VH Neurons at 3 and $4 \mathrm{~mm}$ Rostral to the Injury Epicenter of Each Rat

Figure 10. Linear regression analysis of the relationship between the number of $\mathrm{VH}$ neurons at 3 and $4 \mathrm{~mm}$ rostral to the lesion epicenter and $\mathrm{CO}_{2}$-triggered changes of $\mathrm{Vt}$. There is a significant correlation $(r=0.522$; $p=0.003$ ) between the total number of $\mathrm{VH}$ neurons at 3 and $4 \mathrm{~mm}$ rostral to the lesion epicenter and the change of $\mathrm{Vt}\left(\mathrm{Vt}_{7}\right.$ d p.i. $\left.-\mathrm{Vt}_{\text {preinjury }}\right)$ in response to the breathing of $5 \% \mathrm{CO}_{2}$ for rats at $7 \mathrm{~d}$ after SCI. Analysis was based on eight rats from the FGF2-treated group (๑) and seven rats from the VEH-treated group $(\bigcirc)$.

to its ability to preserve $\mathrm{VH}$ motor neurons just rostral to the injury site.

This is the first report of the effects of experimental spinal cord contusion injury on respiratory function in conscious rats. Although most of the morbidity and mortality after human SCI, at both acute and chronic stages, is caused by respiratory dysfunc- tion (Slaok and Shuoart, 1994; Frankel et al., 1998), there is little information on the effects of SCI on respiration in clinically relevant animal models. The only previous report of which we are aware examined phrenic nerve activity in anesthetized, vagotomized, paralyzed, and artificially ventilated rats 2-5 weeks after cervical contusion injuries (El-Bohy et al., 1998). Such studies provide important information but are necessarily terminal. In the present study, using a plethysmograph, we were able to evaluate respiration in conscious rats before and repeatedly at different times after a standardized SCI.

Measuring respiration in conscious rats required careful acclimatization of the animals to the plethysmograph body cylinder (see Fig. 1a,b) and strict control of recording conditions to ensure consistent results. Acclimatization was necessary to achieve absence of motion artifacts and signs of stress. Furthermore, rats were evaluated at the same time of day and in a room where they were isolated from noise, activity, and other rats. Under these conditions, our data showed small SEs, were similar between the two experimental groups at $1 \mathrm{~d}$ before injury (Figs. 3, 4), and were consistent with data reported by others (Baker et al., 1979).

We showed that respiration in the conscious rats was sensitive to injury at $\mathrm{T} 8$, especially when the rats were challenged to increase their ventilation in response to $\mathrm{CO}_{2}$. Even though $\mathrm{Ve}$ at $24 \mathrm{hr}$ was similar to the preinjury level, the kind of pathophysiological combination of reduced $\mathrm{Vt}$ and increased $f$ that was found in the VEH-treated rats after SCI may be detrimental to gas exchange (Guyton, 1991). Indeed, ventilation perfusion mismatching and hypoxemia without hypoventilation, i.e., with a normal $\mathrm{PCO}_{2}$ of arterial blood have been described in patients with SCI (Ledsome and Sharp, 1981; Mansel and Norman, 1990).

The compromised respiration we saw was associated with the loss of ventral motor neurons at and near the T8 injury site. Ventral motoneurons at thoracic levels innervate both the intercostal (motoneurons at $\mathrm{T}_{1}-\mathrm{T}_{13}$ ) and abdominal muscles [motoneurons at $\mathrm{T}_{5}-\mathrm{L}_{3}$ (Holstege, 1991)]. The intercostal muscles 
have an important respiratory function, and their paralysis causes significant alterations in the elastic properties of the lungs and reduces the outward elastic recoil of the rib cage (Gibson et al., 1977; Troyer and Heilporn, 1980). For instance, patients with quadriplegia caused by SCI below C5 with detectable intercostal electromyographic activity had much better respiratory function than do those who lost it (Troyer and Heilporn, 1980). Thus, respiratory effects were expected for T8 SCI because of loss of thoracic motoneurons, as well as the loss of white matter containing supraspinal control pathways to respiratory motoneurons below the injury site.

The abnormal respiratory pattern in SCI rats is consistent with that found in patients with lower thoracic SCI (Prakash, 1989). The combination of a lower $\mathrm{Vt}$ and a greater $f$ is also seen in patients with respiratory muscle weakness (Gibson et al., 1977), muscular dystrophy (ВФgin et al., 1980), and myotonic dystrophy (BФgin et al., 1980) and can be mimicked by chest strapping (Caro et al., 1960). Patients with myotonic dystrophy also have deficits in ventilatory response to $\mathrm{CO}_{2}$ (BФgin et al., 1980) similar to our rats. Furthermore, in amyotrophic lateral sclerosis the symptoms of a decrease in $\mathrm{Vt}$ and a increase in $f$ are associated with loss of VH neurons (Vitacca et al., 1997). Therefore, the respiratory abnormality of the $\mathrm{VEH}$-treated rats was likely caused by denervation of intercostal muscles via the loss of $\mathrm{VH}$ neurons.

We demonstrated that FGF2 focally injected into the injury site completely eliminated the respiratory deficits triggered by SCI. This effect was correlated with the ability of FGF2 to increase the survival of thoracic $\mathrm{VH}$ neurons after injury. We identified a linear correlation between changes of $\mathrm{Vt}$ under $5 \% \mathrm{CO}_{2}$ and the number of $\mathrm{VH}$ neurons rostral to the injury epicenter. Being rostral to the injury site, these neurons are very likely still connected to the brainstem and hence were able to respond to $\mathrm{CO}_{2}$ challenge (Feldman and McCrimmon, 1999). We also found that FGF2 increased the number of IML neurons after SCI and mitigated denervation of their target (i.e., the adrenal medulla), as evaluated by retrograde labeling with Fluoro-Gold. However, the single focal treatment with FGF2 did not significantly improve hindlimb function (Fig. 6) or increase WM sparing at the epicenter (Fig. 7), consistent with the well-established relationship between white matter sparing and hindlimb function in this model of SCI (Noble and Wrathall, 1985).

The potential mechanism by which FGF2 exerts neuroprotection remains to be established. Both $\mathrm{VH}$ and IML neurons have high-affinity FGF receptors (Blottner et al., 1997). FGF2 has been shown to prevent EAA-mediated neuronal cell death in several neuronal populations (Frim et al., 1993; Kirschner et al., 1995; Mattson et al., 1995), possibly by downregulating NMDA receptor function (Brandoli et al., 1998). Because EAA appear to contribute significantly to secondary tissue loss after SCI (Gomez-Pinilla et al., 1989; Wrathall et al., 1992, 1994), FGF2 may be protective by reducing injury-triggered excitotoxic damage. Overall, our data suggest that FGF2 can be effective as a new strategy to preserve neurons after SCI.

The gradual recovery of respiration that we observed in the VEH-treated group is consistent with what occurs in SCI patients (Bluechardt et al., 1992). Clinically, respiratory recovery eventually allows most SCI patients to be independent of respirator support. Unfortunately, little is known about mechanisms underlying respiratory recovery. It is well established that a diaphragm that is hemiparetic ipsilateral to a hemisected cord (e.g., at C2) can refunction in a few hours after the contralateral phrenic nerve is transected (Lewis and Brookhart, 1951; Guth, 1976). This so-called crossed phrenic phenomenon works by reactivating silent synapses (O'Hara and Goshgarian, 1991; Moreno et al., 1992; Liou and Goshgarian, 1994). Because our VEH-treated animals still exhibited profound respiratory deficits at $7 \mathrm{~d}$ p.i., it seems unlikely that their recovery was mediated by the mechanism that produces the crossed phrenic phenomenon.

However, other types of plasticity triggered by injury develop with a slower time course. For example, enhancement of serotonergic innervation of phrenic motoneurons was found at $28 \mathrm{~d}$ after cervical dorsal rhizotomy (Kinkead et al., 1998) and accounted for long-term facilitation of respiratory motor output. Upregulation of the serotonin system in the thoracic and cervical spinal cord has been suggested to enhance phrenic and intercostal motoneuron excitability and compensate for functional deficits caused by deafferentation (McCrimmon et al., 1995; Turner et al., 1997). Because serotonin is also abnormally increased in spinal segments rostral to a complete transection (Shapiro et al., 1995), serotonin plasticity could play a role in the recovery of respiration in our VEH-treated animals. Another mechanism that may contribute to the recovery of respiration is neuron-muscle reorganization in which muscles denervated because of the death of $\mathrm{VH}$ neurons become reinnervated by adjacent surviving VH neurons over 4 weeks p.i. (Nakamura et al., 1996). Endogenous FGF2 could potentially be involved in both of these types of neural plasticity after SCI. SCI increases levels of FGF2 mRNA and protein expression adjacent to the injury epicenter over the first 24 hr p.i. (Follesa et al., 1994; Mocchetti et al., 1996). Moreover, FGF2 immunoreactivity is seen surrounding surviving $\mathrm{VH}$ neurons at $24 \mathrm{hr}$ after SCI (Mocchetti et al., 1996). FGF2 seems to be important for cholinergic sprouting because application of FGF2 antibody prevents injury-triggered cholinergic sprouting in the hippocampus (Fagan et al., 1997). FGF2 has also been suggested to have a trophic role for serotonergic neurons of the raphe nuclei (Chadi et al., 1993). Understanding the relative role of different natural recovery mechanisms may support the development of therapies to speed up respiratory recovery and therefore minimize the morbidity associated with respiratory deficits after SCI.

In summary, our study has provided the first description of the effects of a clinically relevant animal model of SCI on respiratory function over a period of 5 weeks after injury. It also demonstrates that a single acute dose of FGF2 has long-term effects in sparing neurons and preserving their function after SCI. The potential of FGF2 to improve respiratory function via rescuing $\mathrm{VH}$ motor neurons may offer a new chance to reduce morbidity and improve the quality of life after SCI.

\section{REFERENCES}

Baker HJ, Lindsey JR, Weisbroth SH (1979) The laboratory rat, biology and diseases, pp 411-412. Orlando, FL: Academic.

Basso DM, Beattie MS, Bresnahan JC (1995) A sensitive and reliable locomotor rating scale for open field testing in rats. J Neurotrauma 12:1-21.

Basso DM, Beattie MS, Bresnahan JC, Anderson DK, Faden AI, Gruner JA, Holford TR, Hsu CY, Noble LJ, Nockels R, Perot PL, Salzman SK, Young W (1996) MASCIS evaluation of open field locomotor scores: effects of experience and teamwork on reliability. Multicenter Animal Spinal Cord Injury Study. J Neurotrauma 13:343-359.

ВФgin R, Bureau MA, Lupien L, Lemieux B (1980) Control of breathing in Duchenne's muscular dystrophy. Am J Med 69:227-234.

Behrmann DL, Bresnahan JC, Beattie MS, Shah BR (1992) Spinal cord injury produced by consistent mechanical displacement of the cord in rats: behavioral and histologic analysis. J Neurotrauma 9:197-217.

Blottner D, Baumgarten HG (1992) Basic fibroblast growth factor pre- 
vents neuronal death and atrophy of retrogradely labeled preganglionic neurons in vivo. Exp Neurol 118:35-46.

Blottner D, Stapf C, Meisinger C, Grothe C (1997) Localization, differential expression and retrograde axonal transport suggest physiological role of FGF-2 in spinal autonomic neurons of the rat. Eur $\mathbf{J}$ Neurosci 9:368-377.

Bluechardt MH, Wiens M, Thomas SG, Plyley MJ (1992) Repeated measurements of pulmonary function following spinal cord injury. Paraplegia 30:768-774.

Bracken MB, Shepard MJ, Collins WF, Holford TR, Young W, Baskin DS, Eisenberg HM, Flamm E, Leo-Summers L, Maroon PH, Marshall LF, Perot PL, Piepmeier J, Sonntag VKH, Wagner FC, Wilberger JE, Winn HR (1990) A randomized, controlled trial of methylprednisolone or naloxone in the treatment of acute spinal cord injury. N Engl J Med 322:1405-1411.

Brandoli C, Sanna A, De Bernardi MA, Follesa P, Brooker G, Mocchetti I (1998) Brain-derived neurotrophic factor and basic fibroblast growth factor downregulate NMDA receptor function in cerebellar granule cells. J Neurosci 18:7953-7961.

Caro CG, Butler J, DuBois AB (1960) Some effects of restriction of chest cage expansion on pulmonary function in man: an experimental study. J Clin Invest 39:573-583.

Chadi G, Tinner B, Agnati LF, Fuxe K (1993) Basic fibroblast growth factor (bFGF, FGF-2) immunoreactivity exists in the noradrenaline, adrenaline and 5-HT nerve cells of the rat brain. Neurosci Lett 160:171-176.

Crowe MJ, Bresnahan JC, Shuman SL, Masters JN, Beattie MS (1997) Apoptosis and delayed degeneration after spinal cord injury in rats and monkeys. Nat Med 3:73-76.

Dorato MA, Carlson KH, Copple DL (1983) Pulmonary mechanics in conscious Fischer 344 rats: multiple evaluations using nonsurgical techniques. Toxicol Appl Pharmacol 68:344-353.

El-Bohy AA, Schrimsher GW, Reier PJ, Goshgarian HG (1998) Quantitative assessment of respiratory function following contusion injury of the cervical spinal cord. Exp Neurol 150:143-152.

Fagan AM, Suhr ST, Lucidi-Phillipi CA, Peterson DA, Holtzman DM, Gage FH (1997) Endogenous FGF-2 is important for cholinergic sprouting in the denervated hippocampus. J Neurosci 17:2499-2511.

Feldman JL, McCrimmon DR (1999) Neural control of breathing. In: Fundamental neuroscience (Zigmond MJ, Bloom FE, Landis SC, Roberts JL, Squire LR, eds), pp 1063-1090. San Diego: Academic.

Follesa P, Wrathall JR, Mocchetti I (1994) Increased basic fibroblast growth factor mRNA following contusive spinal cord injury. Brain Res Mol Brain Res 22:1-8.

Frankel HL, Coll JR, Charlifue SW, Whitenect GG, Gardner BP, Jamous MA, Krishnan KR, Nuseibeh I, Savic G, Sett P (1998) Long-term survival in spinal cord injury: a fifty year investigation. Spinal Cord 36:266-274.

Frim DM, Uhler TA, Short MP, Ezzedine ZD, Klagsbrun M, Breakefield XO, Isacson O (1993) Effects of biologically delivered NGF, BDNF and bFGF on striatal excitotoxic lesions. NeuroReport 4:367-370.

Gale K, Kerasidis H, Wrathall JR (1985) Spinal cord contusion in the rat: behavioral analysis of functional neurological impairment. Exp Neurol 88:123-134.

Gibson JG, Pride NB, Newsom Davis J, Loh LC (1977) Pulmonary mechanics in patients with respiratory muscle weakness. Am Rev Respir Dis 115:389-395.

Gomez-Pinilla F, Tram H, Cotman CW, Nieto-Sampedro M (1989) Neuroprotective effect of MK-801 and U-50488H after contusive spinal cord injury. Exp Neurol 104:118-124.

Guth L (1976) Functional plasticity in the respiratory pathway of the mammalian spinal cord. Exp Neurol 51:414-420.

Guyton AC (1991) Pulmonary ventilation. In: Textbook of medical physiology, 8th Edition, pp 402-412. Philadelphia: Saunders.

Holstege G (1991) Descending motor pathways and the spinal motor system: limbic and nonlimbic components. Prog Brain Res 87:307-421.

Kerasidis H, Wrathall JR, Gale K (1987) Behavioral assessment of functional deficit in rats with contusive spinal cord injury. J Neurosci Methods 20:167-189.

Kinkead R, Zhan WZ, Prakash YS, Bach KB, Sieck GC, Mitchell GS (1998) Cervical dorsal rhizotomy enhances serotonergic innervation of phrenic motoneurons and serotonin-dependent long-term facilitation of respiratory motor output in rats. J Neurosci 18:8436-8443.

Kirschner PB, Henshaw R, Weise J, Trubetskoy V, Finklestein S, Schulz JB, Beal MF (1995) Basic fibroblast growth factor protects against excitotoxicity and chemical hypoxia in both neonatal and adult rats. J Cereb Blood Flow Metab 15:619-623.

Koo EH, Hoffman PN, Price DL (1988) Levels of neurotransmitter and cytoskeletal protein mRNAs during nerve regeneration in sympathetic ganglia. Brain Res 449:361-363.

Kurtzke JF (1977) Epidemiology of spinal cord injury. Neurol Neurocir Psiquiatr 18:157-191.

Ledsome JR, Sharp JM (1981) Pulmonary function in acute cervical spinal cord injury. Am Rev Respir Dis 124:41-44.

Lewis LJ, Brookhart JM (1951) Significance of the crossed phrenic phenomenon. Am J Physiol 166:241-254.

Liou WW, Goshgarian GH (1994) Quantitative assessment of the effect of chronic phrenicotomy on the induction of the crossed phrenic phenomenon. Exp Neurol 127:145-153.

Liu XZ, Xu XM, Hu R, Du C, Zhang SX, McDonald JW, Dong HX, Wu YJ, Fan GS, Jacquin MF, Hsu CY, Choi DW (1997) Neuronal and glial apoptosis after traumatic spinal cord injury. J Neurosci 17:5395-5406.

Mansel JK, Norman JR (1990) Respiratory complications and management of spinal cord injuries. Chest 97:1446-1452.

Mattson MP, Lovell MA, Furukawa K, Markesbery WR (1995) Neurotrophic factors attenuate glutamate-induced accumulation of peroxides, elevation of intracellular $\mathrm{Ca}^{2+}$ concentration, and neurotoxicity and increase antioxidant enzyme activities in hippocampal neurons. J Neurochem 65:1740-1751.

McCrimmon DR, Dekin MS, Mitchell GS (1995) Glutamate, GABA, and serotonin in ventilatory control. In: Regulation of breathing (Dempsey JA, Pack AI, eds), pp 151-218. New York: Dekker.

Mocchetti I, Rabin SJ, Colangelo AM, Whittemore SR, Wrathall JR (1996) Increased basic fibroblast growth factor expression following contusive spinal cord injury. Exp Neurol 141:154-164.

Monteau R, Hilaire G (1991) Spinal respiratory motoneurons. Prog Neurobiol 37:83-144.

Moreno DE, Yu XJ, Goshgarian HG (1992) Identification of the axon pathways which mediate functional recovery of a paralyzed hemidiaphragm following spinal cord hemisection in the adult rat. Exp Neurol 116:219-228.

Moyer JA, Wood A, Zaleska MM, Ay I, Finklestein SP, Protter AA (1998) Basic fibroblast growth factor: a potential therapeutic agent for the treatment of acute neurodegenerative disorders and vascular insufficiency. Exp Opin Ther Patents 8:1425-1445.

Nakamura M, Fujimura Y, Yato Y, Watanabe M (1996) Muscle reorganization following incomplete cervical spinal cord injury in rats. Spinal Cord 34:752-756.

Noble LJ, Wrathall JR (1985) Spinal cord contusion in the rat: morphometric analyses of alterations in the spinal cord. Exp Neurol 88:135-149.

Noble LJ, Wrathall JR (1989a) Correlative analysis of lesion development and functional status after graded spinal cord contusive injuries in the rat. Exp Neurol 103:34-40.

Noble LJ, Wrathall JR (1989b) Distribution and time course of protein extravasation in the spinal cord after contusive injury. Brain Res 482:57-66

O'Hara TE, Goshgarian GH (1991) Quantitative assessment of phrenic nerve functional recovery mediated by the crossed phrenic reflex at various time intervals after spinal cord injury. Exp Neurol 111:244-250.

Panjabi M, Wrathall JR (1988) Biomechanical analysis of spinal cord injury and functional loss. Spine 13:1365-1370.

Prakash UBS (1989) Neurologic diseases. In: Textbook of pulmonary diseases, 4th Edition, Vol 2 (Baum GL, Wolinsky E, eds), pp 14091436. Boston: Little, Brown.

Riggins RS, Kraus JF (1977) The risk of neurologic damage with fractures of the vertebrae. J Trauma 17:126-133.

Saji M, Miura M (1990) Thoracic excitatory motor neurons of the rats: localization and sites of origin of their premotor neurons. Brain Res 507:247-253.

Schramm LP, Adair JR, Stribling JM, Gray LP (1975) Preganglionic innervation of the adrenal gland of the rat: a study using horseradish peroxidase. Exp Neurol 49:540-553.

Shapiro S, Kubek M, Siemers E, Daly E, Callahan J, Putty T (1995) Quantification of thyrotropin-releasing hormone changes and serotonin content changes following graded spinal cord injury. J Surg Res 59:393-398. 
Shapiro SS, Wilk MB (1965) An analysis of variance test of normality. Biometrika 52:591-612.

Slaok RS, Shuoart W (1994) Respiratory dysfunction associated with traumatic injury to the central nervous system. Clin Chest Med 15:739-749.

Sofroniew MV, Cooper JD, Svendsen CN, Crossman P, Ip NY, Lindsay RM, Zafra F, Lindholm D (1993) Atrophy but not death of adult septal cholinergic neurons after ablation of target capacity to produce mRNAs for NGF, BDNF, and NT3. J Neurosci 13:5263-5276.

Teng YD, Wrathall JR (1997) Local blockade of sodium channels by tetrodotoxin ameliorates tissue loss and long-term functional deficits resulting from experimental spinal cord injury. $\mathrm{J}$ Neurosci 17:4359-4366.

Teng YD, Mocchetti I, Taveira-DaSilva AM, Gillis RA, Wrathall JR (1998a) Basic and acidic fibroblast growth factor (FGF2) improves respiratory function after contusive spinal cord injury-a doseresponse study. J Neurotrauma 15:899.

Teng YD, Mocchetti I, Wrathall JR (1998b) Basic and acidic fibroblast growth factors protect spinal motor neurons in vivo after experimental spinal cord injury. Eur J Neurosci 10:798-802.

Troyer AD, Heilporn A (1980) Respiratory mechanics in quadriplegia. The respiratory function of the intercostal muscles. Am Rev Respir Dis 122:591-600.
Turner DL, Bach KB, Martin PA, Olsen EB, Brownfield M, Foley KT, Mitchell GS (1997) Modulation of ventilatory control during exercise. Respir Physiol 110:277-285.

Vitacca M, Clini E, Facchetti D, Pagani M, Poloni M, Porta R, Ambrosino N (1997) Breathing pattern and respiratory mechanics in patients with amyotrophic lateral sclerosis. Eur Respir J 10:1614-1621.

Wrathall JR (1996) Weight-drop models of experimental spinal cord injury. In: Neurotrauma (Narayan RK, Wilberger JE, Povlishock JT, eds), pp 1381-1394. New York: McGraw.

Wrathall JR, Pettegrew R, Harvey F (1985) Spinal cord contusion in the rat: production of graded, reproducible injury groups. Exp Neurol 88:108-122.

Wrathall JR, Teng YD, Choiniere D, Mundt D (1992) Evidence that local non-NMDA receptors contribute to functional deficits in contusive spinal cord injury. Brain Res 586:140-143.

Wrathall JR, Choiniere D, Teng YD (1994) Dose-dependent reduction of tissue loss and functional impairment after spinal cord trauma with the AMPA/kainate antagonist NBQX. J Neurosci 14:6598-6607.

Wrathall JR, Li W, Hudson LD (1998) Myelin gene expression after experimental contusive spinal cord injury. J Neurosci 18:8780-8793.

Young W (1993) Secondary injury mechanisms in acute spinal cord injury. J Emerg Med 11:13-22. 